\title{
Functional outcome in pediatric hydrocephalus: results of applying the Spanish version of the Hydrocephalus Outcome Questionnaire
}

\author{
*Sara Iglesias, MD, PhD, Bienvenido Ros, MD, PhD, ${ }^{1}$ Álvaro Martín, MD, PhD, ${ }^{1}$ \\ Antonio Carrasco, MD, ${ }^{1}$ Francisca Rius, $\mathrm{PhD},{ }^{2}$ and Miguel Ángel Arráez, MD, PhD ${ }^{1}$ \\ 1Neurosurgery Department, Hospital Regional Universitario de Málaga; and ${ }^{2}$ Statistics Department, Universidad de Málaga,
Spain
}

\begin{abstract}
OBJECTIVE The aims of the study were to assess whether the Spanish version of the Hydrocephalus Outcome Questionnaire (HOQ) could be useful for the evaluation and comparison of outcomes in the patients in the authors' region with those in patients in other institutions and to analyze predictors of functional outcome in patients with a shunt.

METHODS The authors performed this cross-sectional study between March 2015 and April 2016. All the parents of a pediatric patient with hydrocephalus who attended the Hospital Regional Universitario de Málaga neurosurgery outpatient clinic were invited to enroll in the study and complete the HOQ-Spanish version. Age at diagnosis and at the time of the study, clinical data, shunt complications, and socioeconomic factors were also recorded. A descriptive analysis was performed, and independent variables related to the $\mathrm{HOQ}$ scores were studied.
\end{abstract}

RESULTS A total of 132 patients participated in the study (100\% participation rate). The mean ages were 16.74 months (range 0-142 months) at diagnosis and 10.45 years (range 5-16 years) at the time of the study. The mean overall $\mathrm{HOQ}$ score was 0.68 (on a scale from 0 [worse] to 1.0 [best]). Factors related to a worse quality of life were seizures, motor or visual impairment, shunt infection, need for shunt revision, need for more than 2 shunt revisions (range $0-8$ revisions), symptomatic overdrainage, and older age at the time of the study.

CONCLUSIONS The HOQ-Spanish version is useful in the authors' region; the dimension scores found in this study were comparable to those previously reported by referral centers. Future goals should be to prevent shunt complications, routinely get children to reach functional status, and refer patients for adjuvant therapy promptly.

https://thejns.org/doi/abs/10.3171/2017.8.PEDS16700

KEY WORDS quality of life; Hydrocephalus Outcome Questionnaire; pediatric hydrocephalus; functional outcome; health

$\mathrm{T}$ HE definition of functional outcome in pediatric patients with hydrocephalus has included associated physical, social-emotional, and cognitive morbidities that can affect the quality of life of these patients. ${ }^{10}$ Concern about this issue has increased in the neurosurgical community over the past 20 years, although the relevant scientific literature remains scarce compared with that regarding the technical aspects of shunt surgery. Although hydrocephalus represents an injury to the developing brain, it is difficult to correlate such morphological changes with the outcome of the patient. ${ }^{20,26}$ Possible out- comes have been described, including discussion of physical health problems; ${ }^{28}$ cognitive impairment related to not only the patient's intelligence quotient but also visuospatial functions, motor skills, and nonverbal intelligence; ${ }^{20}$ and behavior problems that can compromise the social integration of affected children. ${ }^{5,27}$

A few prognostic factors were reported in the 1990s and early $2000 \mathrm{~s},{ }^{3-5,19-21,26,27}$ but a lack of consensus about the scales used to evaluate these patients has made comparing the results difficult. ${ }^{4,19}$ In addition, this type of scale needs to be applied for some time before it can be con-

* Drs. Martín and Carrasco contributed equally to this work. 
sidered reliable, valid, and sensitive, and the use of established instruments is recommended..$^{9}$ In 2004 Kulkarni et al. ${ }^{15}$ described the Hydrocephalus Outcome Questionnaire (HOQ). This valid and easy-to-complete scale measures quality of life in pediatric patients with hydrocephalus at a single point in time. Since then, this group has undertaken several studies using the HOQ to evaluate the prognosis of pediatric patients with hydrocephalus at the Hospital for Sick Children in Toronto, ${ }^{12,14,16,17}$ although only 2 papers have been published by other teams that used this valuable instrument. ${ }^{1,24}$

Accordingly, the aims of this study were to assess whether the Spanish version of the HOQ could be useful for the evaluation of these patients in our region, to compare the quality of life of the patients followed at our institution with that of other patients elsewhere, and to analyze predictors of functional outcome of pediatric patients after shunt placement.

\section{Methods \\ Patient Population}

Between March 2015 and April 2016, all parents of a child with hydrocephalus who was treated with a ventriculoperitoneal shunt and followed up regularly as an outpatient of the Hospital Regional Universitario de Málaga Pediatric Neurosurgery Department were invited to participate in the study. All the patients were at least 5 years old (school aged), had not undergone any insertion or revision surgery for at least 6 months, and were clinically stable. Patients were excluded if they had been treated at any time at any other center. The parents of these 132 patients agreed to enroll their child in the study (100\% participation rate). Ethical approval was obtained from the Hospital Regional Universitario de Málaga.

\section{Data Collection}

Clinical data were obtained from our pediatric hydrocephalus database or from the parents at the same time that they completed the HOQ-Spanish version. Clinical data collectors were blinded to the HOQ data at the time of data collection.

Each patient's condition was classified as posthemorrhage, postinfection, tumor-associated, spinal dysraphism-associated, primary, or dysgenetic hydrocephalus or other type of secondary hydrocephalus. Age at first shunt surgery and age at the time of HOQ completion were recorded. History of seizures and vision, hearing, or motor impairment was recorded also. Seizures with neurophysiological confirmation and antiepileptic treatment were considered, and intractable seizures were studied separately. Visual impairment was defined as blindness or difficulty seeing or differentiating objects from a short distance, despite best possible correction, secondary to low visual acuity or campimetric deficit diagnosed by an ophthalmologist. Permanent impairment in hearing was confirmed with an audiogram or auditory evoked potentials. Motor function impairment included cerebral palsy (different degrees) and partial or complete lower-limb paralysis secondary to spina bifida.

An analysis of shunt-related complications, including symptomatic overdrainage, shunt infection, shunt failure, and number of shunt failures, was performed. Symptomatic overdrainage was defined as any episodic symptoms that improved after increasing valve outflow resistance, with or without the need for a surgical revision of the system.

Shunt infection was defined as follows, as previously reported by the Hydrocephalus Clinical Research Network: ${ }^{8}$ 1) identification of an infectious organism by culturing or Gram staining of CSF, wound swab, or pseudocyst fluid; 2) shunt erosion (defined as wound breakdown with visible shunt hardware); 3) abdominal pseudocyst (even in the absence of positive culture results); or 4) positive blood culture for a child with a ventriculoatrial shunt. A culture was performed for each patient who was thought to have a clinical shunt infection. Shunt failure was defined as any clinical event that was followed by shunt-revision surgery.

Accessibility to the Hospital Regional Universitario de Málaga was measured using the shortest distance by road from the patient's residence. The socioeconomic variables measured were adjuvant care and parental education. Adjuvant care was divided into the following 5 categories: 1) parents know that adjuvant treatment would be beneficial but their child does not receive it (access problems), 2) physical therapy, 3) neuropsychological therapy, 4) both types of therapy, and 5) treatment is not needed after patient evaluation by the multidisciplinary unit.

The categorization of parental education was based on the International Standard Classification of Education (ISCED), developed by the United Nations Educational, Scientific and Cultural Organization (UNESCO) in the 1970s to serve as a statistical framework for information on education both within individual countries and internationally. For simplification, we grouped different 2011 ISCED levels of education as follows: preprimary education (attended school but did not obtain the primary education certificate [the parents in our study with this classification had basic literacy skills]), primary education, secondary education (lower and/or upper and postsecondary education), and tertiary education (short-cycle program or bachelor, master, doctoral, or equivalent degree).

The HOQ is a reliable and previously validated measure of quality of life developed by the Division of Neurosurgery at Toronto's Hospital for Sick Children. ${ }^{15}$ It is a 51-item instrument that is completed by the parents of children with hydrocephalus. For our study, we used the HOQ-Spanish version posted to us by the author (A.V. Kulkarni) with slight changes in the translation to adapt it to the Spanish language used in Spain (Table 1) (the English version of the HOQ is provided in Table 2). Given that parental education level was not an inclusion criterion and to avoid possible misunderstandings or wider variability, it was almost always the same pediatric neurosurgeon (S.I.) who explained the questionnaire to the parent (mother or father) and verified that he or she understood it before completing it in the presence of the same person or a trained researcher. Responses to the HOQ questions are given a score that ranges from 0 (worse health status) to 4 (better health status). The scores for each item are added and then divided by the highest possible summed score to provide a final score (as provided by Kulkarni et al. ${ }^{14}$ ) for the 4 health aspects considered, namely, physi- 
TABLE 1. HOQ-Spanish version

Por favor, RELLENE EL CÍRCULO que mejor represente su respuesta sobre CÓMO SON DE CIERTAS las siguientes AFIRMACIONES sobre SU HIJO/A durante las últimas 4 semanas.

\begin{tabular}{|c|c|c|c|c|c|}
\hline Mi hijo/a & $\begin{array}{l}\text { Para Nada } \\
\text { Cierto }\end{array}$ & $\begin{array}{l}\text { Un Poquito } \\
\text { Cierto }\end{array}$ & $\begin{array}{l}\text { Algo } \\
\text { Cierto }\end{array}$ & $\begin{array}{c}\text { Bastante } \\
\text { Cierto }\end{array}$ & $\begin{array}{l}\text { Muy } \\
\text { Cierto }\end{array}$ \\
\hline Necesita ayuda para vestirse & 0 & 0 & 0 & 0 & 0 \\
\hline Necesita ayuda para ir al baño & 0 & 0 & 0 & 0 & 0 \\
\hline Tiene visión pobre & 0 & 0 & 0 & 0 & 0 \\
\hline Tiene dificultades para caminar & 0 & 0 & 0 & 0 & 0 \\
\hline Requiere una silla de ruedas & 0 & 0 & 0 & 0 & 0 \\
\hline Tiene dificultades para participar en deportes & 0 & 0 & 0 & 0 & 0 \\
\hline Tiene dificultades para escribir & 0 & 0 & 0 & 0 & 0 \\
\hline Tiene un equilibrio pobre & 0 & 0 & 0 & 0 & 0 \\
\hline Tiene dificultad para atarse los cordones de los zapatos & 0 & 0 & 0 & 0 & 0 \\
\hline Se cansa fácilmente & 0 & 0 & 0 & 0 & 0 \\
\hline Tiene dificultades para hablar & 0 & 0 & 0 & 0 & 0 \\
\hline Sufre de dolores de cabeza & 0 & 0 & 0 & 0 & 0 \\
\hline Tiene convulsiones frecuentes & 0 & 0 & 0 & 0 & 0 \\
\hline Necesita ayuda para bañarse & 0 & 0 & 0 & 0 & 0 \\
\hline Necesita ayuda para comer & 0 & 0 & 0 & 0 & 0 \\
\hline Tiene dificultades para participar en actividades extracurriculares (juegos, culturales) & 0 & 0 & 0 & 0 & 0 \\
\hline Se siente observado cuándo está en público & 0 & 0 & 0 & 0 & 0 \\
\hline Tiene dificultades para separarse de mi & 0 & 0 & 0 & 0 & 0 \\
\hline Tiene muchos amigos & 0 & 0 & 0 & 0 & 0 \\
\hline Es tratado como igual por sus compañeros & 0 & 0 & 0 & 0 & 0 \\
\hline Es capaz de visitar a sus amigos & 0 & 0 & 0 & 0 & 0 \\
\hline Es solitario/a o introvertido/a & 0 & 0 & 0 & 0 & 0 \\
\hline Tiene dificultades para reconocer las consecuencias de sus acciones & 0 & 0 & 0 & 0 & 0 \\
\hline Falta mucho a la escuela por su enfermedad & 0 & 0 & O & 0 & 0 \\
\hline Se pone ansioso en situaciones sociales & 0 & 0 & 0 & 0 & 0 \\
\hline Tiene dificultades para llevarse bien con sus compañeros & 0 & 0 & 0 & 0 & 0 \\
\hline Es tímido/a en público & 0 & 0 & 0 & 0 & 0 \\
\hline Tiene dificultades para jugar con sus compañeros & O & 0 & 0 & 0 & 0 \\
\hline Se frustra fácilmente & 0 & 0 & 0 & 0 & 0 \\
\hline Tiene dificultades para expresar verbalmente sus sentimientos & 0 & 0 & 0 & 0 & 0 \\
\hline A menudo se siente estresado & 0 & 0 & 0 & 0 & 0 \\
\hline A menudo está irritable & 0 & 0 & 0 & 0 & 0 \\
\hline Está desmotivado/a & 0 & 0 & 0 & 0 & 0 \\
\hline Está preocupado/a acerca de su apariencia física & 0 & 0 & 0 & 0 & 0 \\
\hline A menudo se siente triste & 0 & 0 & 0 & 0 & 0 \\
\hline Se preocupa acerca del futuro & 0 & 0 & 0 & 0 & 0 \\
\hline A menudo está nervioso/a & 0 & 0 & 0 & 0 & 0 \\
\hline Le falta confianza en sí mismo/a & 0 & 0 & 0 & 0 & 0 \\
\hline Reacciona exageradamente con las enfermedades de los demás & 0 & 0 & 0 & 0 & 0 \\
\hline Tiene un pobre concepto del tiempo & 0 & 0 & 0 & 0 & 0 \\
\hline Tiene dificultades con las matemáticas & 0 & 0 & 0 & 0 & 0 \\
\hline Es organizado/a & 0 & 0 & 0 & 0 & 0 \\
\hline Tiene dificultades para concentrarse & 0 & 0 & 0 & 0 & 0 \\
\hline Se le olvidan las cosas & 0 & 0 & 0 & 0 & 0 \\
\hline Tiene dificultades para realizar varias tareas seguidas & 0 & 0 & 0 & 0 & 0 \\
\hline Tiene dificultades para leer & 0 & 0 & 0 & 0 & 0 \\
\hline
\end{tabular}


» CONTINUED FROM PAGE 226

TABLE 1. HOQ-Spanish version

Por favor, RELLENE EL CÍRCULO que mejor represente su respuesta sobre CÓMO SON DE CIERTAS las siguientes AFIRMACIONES sobre SU HIJO/A durante las últimas 4 semanas.

\begin{tabular}{|c|c|c|c|c|c|}
\hline Mi hijo/a & $\begin{array}{c}\text { Para Nada } \\
\text { Cierto }\end{array}$ & $\begin{array}{c}\text { Un Poquito } \\
\text { Cierto }\end{array}$ & $\begin{array}{l}\text { Algo } \\
\text { Cierto }\end{array}$ & $\begin{array}{c}\text { Bastante } \\
\text { Cierto }\end{array}$ & $\begin{array}{l}\text { Muy } \\
\text { Cierto }\end{array}$ \\
\hline Aprende lentamente & 0 & 0 & 0 & 0 & 0 \\
\hline Necesita que le repitan las instrucciones & 0 & 0 & O & 0 & O \\
\hline Olvida sus rutinas diarias & 0 & 0 & 0 & 0 & 0 \\
\hline Tiene dificultades para aprender nuevas tareas & 0 & 0 & 0 & 0 & 0 \\
\hline Pierde la atención fácilmente & 0 & 0 & 0 & 0 & 0 \\
\hline
\end{tabular}

cal, social-emotional, cognitive, and overall health; the total HOQ score also ranges from 0 (worse quality of life) to 1 (best quality of life). To make comparisons with the general population, we also calculated a utility score from the overall health score using the following formula (as

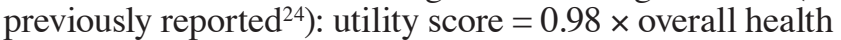
score +0.1 .

\section{Statistical Analysis}

To test the reliability of the HOQ-Spanish version, the results of the completed HOQ questionnaires were used to calculate internal consistency with the Cronbach alpha model. Descriptive data from our analyses are presented as percentages and numbers for qualitative variables and means, standard deviations, and percentiles for scale variables. The associations between HOQ health scores (physical, social-emotional, cognitive, and overall) and independent variables considered to be factors were analyzed using parametric tests (ANOVA and/or the Student t-test) or nonparametric tests (Kruskal-Wallis and/or MannWhitney test), depending on the number of levels of the factor. When the ANOVA results were significant, multiple comparisons were performed using the Tukey test. Linear relationships between quantitative variables were studied with the Pearson rank correlation test. A probability value less than 0.05 was considered statistically significant. All statistical analyses were performed using IBM SPSS 23.0 software (IBM Corp.)

\section{Results}

\section{Patient Characteristics and Descriptive Data}

Of the 166 patients followed regularly in our external clinics, $132(79.52 \%)$ were eligible after screening. The parents of all 132 children agreed to participate $(100 \%$ overall participation rate). The main reasons for exclusion were that the children were younger than 5 years or their follow-up duration was less than 6 months. Patient characteristics are listed in Table 3. Shunt infection was found in $13.6 \%$ of the patients and was related to previous surgery (less than 1 year before) or abdominal complications (pseudocysts). For $10.6 \%$ of the patients, the etiology of the hydrocephalus was infection. The mean age at first surgery was $16.74 \pm 33.25$ months (range 0-142 months) and at the time of the study was $10.45 \pm 3.19$ years (range 5-16 years). The median age at the time of the study was
10 years. The mean number of shunt revisions was 1.80 (range 0-8), and their distribution is shown in Table 4. The mean distance from the patient's house to the hospital was $58.11 \mathrm{~km}$ (range $1-264 \mathrm{~km})$. Only $3(2.3 \%)$ of the patients were living in Morocco. The mean HOQ scores are listed in Table 5, and their distribution is shown in Fig. 1.

\section{Testing of Reliability of the HOQ-Spanish version}

The internal consistency according to the Cronbach alpha model is presented in Table 6. The Cronbach alpha model is a coefficient of internal consistency (i.e., how closely related a set of items are as a group) and is considered to be a measure of scale reliability. A reliability coefficient of 0.70 or higher is considered acceptable in most studies.

\section{Association Between Dichotomous Independent Variables and $\mathrm{HOQ}$ Scores}

The HOQ physical health score was significantly related to a history of seizures and visual or motor impairment. Previous shunt-revision surgery and shunt infection were related to worse HOQ physical health scores. Potential predictors of a worse HOQ social-emotional score were a history of seizures and visual or motor impairment. Factors associated with a worse HOQ cognitive score were again seizures and motor or visual deficits, in addition to shunt infection and symptomatic overdrainage. These results are summarized in Table 7.

\section{Association Between Nondichotomous Independent Variables and HOQ Scores}

Regarding the etiology of hydrocephalus and HOQ scores, we did not find any significant difference. Box plots that show the relationships between the health scores and the hydrocephalus etiology are provided in Fig. 2.

We found no significant association between the level of parental education stratified according to 4 categories (preprimary, primary, secondary, or tertiary education) and the quality of life of the pediatric patients with hydrocephalus (Fig. 3). To simplify the analysis, HOQ scores related to parental education dichotomized as attainment of undergraduate or graduate/professional degree were studied also, but those results also were not significant (Table 7).

The type of adjuvant therapy given to the patients was 
TABLE 2. HOQ-English version

Please FILL IN THE CIRCLE that best represents your answer to HOW TRUE the following STATEMENTS are about YOUR CHILD over the last 4 WEEKS.

\begin{tabular}{|c|c|c|c|c|c|}
\hline My child & Not at All True & A Little True & Somewhat True & Quite a Bit True & Very True \\
\hline Needs help dressing & 0 & 0 & 0 & 0 & 0 \\
\hline Needs help going to the washroom & 0 & 0 & 0 & 0 & 0 \\
\hline Has poor vision & 0 & 0 & 0 & 0 & 0 \\
\hline Has difficulty walking & 0 & 0 & 0 & 0 & 0 \\
\hline Needs a wheelchair & 0 & 0 & 0 & 0 & 0 \\
\hline Has difficulty participating in sports & 0 & 0 & 0 & 0 & 0 \\
\hline Has difficulty w/ handwriting & 0 & 0 & 0 & 0 & 0 \\
\hline Has poor physical balance & 0 & 0 & 0 & 0 & 0 \\
\hline Has difficulty tying shoelaces & 0 & 0 & 0 & 0 & 0 \\
\hline Gets tired easily & 0 & 0 & 0 & 0 & 0 \\
\hline Has difficulty speaking & 0 & 0 & 0 & 0 & 0 \\
\hline Suffers from headaches & 0 & 0 & 0 & 0 & 0 \\
\hline Has frequent seizures & 0 & 0 & 0 & 0 & 0 \\
\hline Needs help bathing & 0 & 0 & 0 & 0 & 0 \\
\hline Needs help eating food & 0 & 0 & 0 & 0 & 0 \\
\hline Has difficulty participating in extracurricular activities & 0 & 0 & 0 & 0 & 0 \\
\hline Feels like he/she is stared at in public & 0 & 0 & 0 & 0 & 0 \\
\hline Has difficulty separating from me & 0 & 0 & 0 & 0 & 0 \\
\hline Has many friends & 0 & 0 & 0 & 0 & 0 \\
\hline Is treated as an equal by his/her peers & 0 & 0 & 0 & 0 & 0 \\
\hline Is able to visit friends & 0 & 0 & 0 & 0 & 0 \\
\hline Is solitary \& keeps to him/herself & 0 & 0 & 0 & 0 & 0 \\
\hline Has difficulty recognizing the consequences of his/her actions & 0 & 0 & 0 & 0 & 0 \\
\hline Misses a lot of school due to illness & 0 & 0 & 0 & 0 & 0 \\
\hline Gets anxious in social situations & 0 & 0 & 0 & 0 & 0 \\
\hline Has difficulty getting along $w /$ peers & 0 & 0 & 0 & 0 & 0 \\
\hline Is shy in public & 0 & 0 & 0 & 0 & 0 \\
\hline Has difficulty playing $w /$ peers & 0 & 0 & 0 & 0 & 0 \\
\hline Is easily frustrated & 0 & 0 & 0 & 0 & 0 \\
\hline Has difficulty verbally expressing feelings & 0 & 0 & 0 & 0 & 0 \\
\hline Often feels stressed & 0 & 0 & 0 & 0 & 0 \\
\hline Is often irritable & 0 & 0 & 0 & 0 & 0 \\
\hline Is unmotivated & 0 & 0 & 0 & 0 & 0 \\
\hline Is concerned about his/her physical appearance & 0 & 0 & 0 & 0 & 0 \\
\hline Often feels sad & 0 & 0 & 0 & 0 & 0 \\
\hline Worries about the future & 0 & 0 & 0 & 0 & 0 \\
\hline Is often restless & 0 & 0 & 0 & 0 & 0 \\
\hline Lacks self-confidence & 0 & 0 & 0 & 0 & 0 \\
\hline Overreacts to other people's illnesses & 0 & 0 & 0 & 0 & 0 \\
\hline Has a poor concept of time & 0 & 0 & 0 & 0 & 0 \\
\hline Has difficulty w/ math & 0 & 0 & 0 & 0 & 0 \\
\hline Is well organized & 0 & 0 & 0 & 0 & 0 \\
\hline Has difficulty concentrating & 0 & 0 & 0 & 0 & 0 \\
\hline Is forgetful & 0 & 0 & 0 & 0 & 0 \\
\hline Has difficulty performing several tasks in a row & 0 & 0 & 0 & 0 & 0 \\
\hline Has difficulty reading & 0 & 0 & 0 & 0 & 0 \\
\hline Is a slow learner & 0 & 0 & 0 & 0 & 0 \\
\hline
\end{tabular}


Please FILL IN THE CIRCLE that best represents your answer to HOW TRUE the following STATEMENTS are about YOUR CHILD over the last 4 WEEKS.

\begin{tabular}{lccccc}
\hline \multicolumn{1}{c}{ My child } & Not at All True & A Little True & Somewhat True & Quite a Bit True & Very True \\
\hline Needs instructions repeated & 0 & 0 & 0 & 0 & 0 \\
\hline Forgets daily routines & 0 & 0 & 0 & 0 & 0 \\
\hline Has difficulty learning new tasks & 0 & 0 & 0 & 0 & 0 \\
\hline Has a short attention span & 0 & 0 & 0 & 0 & 0 \\
\hline
\end{tabular}

not significantly associated with the HOQ scores in multiple comparisons. Box plots that show the relationships between the health scores and the adjuvant therapy given are provided in Fig. 4.

\section{Association Between Quantitative Independent Variables and HOQ Scores}

Correlations between the HOQ scores and age at diagnosis, age at the time of the study, number of shunt revisions, and distance from the patient's house to the hospital were analyzed (Table 8). Having undergone more than 2 shunt revisions (range $0-8$ revisions) was a predictor of worse physical outcome, and older age at HOQ completion was related to worse outcome in social and overall scores.

\section{Discussion}

Quality-of-life assessment has become important since pediatric patients with hydrocephalus have experienced improvement in their life expectancy. In fact, a major concern for parents at the time of diagnosis is to know whether their child will be able to lead a useful life. The functional outcome of patients after shunt placement can be related to many factors, which sometimes are liable to be influenced by our practice and other times are not, as in the case of primary diagnosis. Nonetheless, improving our knowledge of this issue could help us counsel families better. ${ }^{2,10,22,28}$

Since 2007, when Platenkamp et al. ${ }^{24}$ developed a clinical study that supported the important initiative of Kulkarni et al. ${ }^{14-16}$ to develop a specific outcome measurement tool for children with hydrocephalus, no other center in the world has used the HOQ to assess functional outcome in patients after shunt placement. Using the same outcome measure in clinical research performed in different centers, including auditing of the results and comparing them with those in international referral hospitals, should help to improve the validity of the HOQ. ${ }^{15}$ Several studies also found that the HOQ has excellent psychometric properties and seems to be suitable for measuring health status..$^{13,14}$

The HOQ-Spanish version was used for this study without formal validation, assuming that the properties of the test would not be affected severely by the translation process, as previously reported by Platenkamp et al. ${ }^{24}$ Internal consistency obtained by using the Cronbach alpha coefficient was similar to that previously reported by Kulkarni et al. ${ }^{15}$

\section{Descriptive Analysis of HOQ Scores}

Our series can be considered to comprise a typical cohort of pediatric patients with hydrocephalus. All the patients were included in our hydrocephalus database and represented $79.52 \%$ (132 of 166) of our center's population of patients with hydrocephalus. The characteristics of this population were described in a previous report. ${ }^{6}$ Only 1 patient in the series was living in an institution, and another was living with a host family. In these cases, the caregivers were asked for consent. However, we decided not to exclude them from our study because they were particularly disabled, and their exclusion could have influenced the results.

We explained to every family that inclusion in the study was absolutely voluntary and independent of the patient's follow-up care and treatment. After we commented on the aims of the investigation, all the families showed interest in participating and thereby contributing to a better understanding of the functional prognosis of pediatric patients with hydrocephalus to improve their child's quality of life as much as possible and to improve the information given to other families at the time of such a diag-
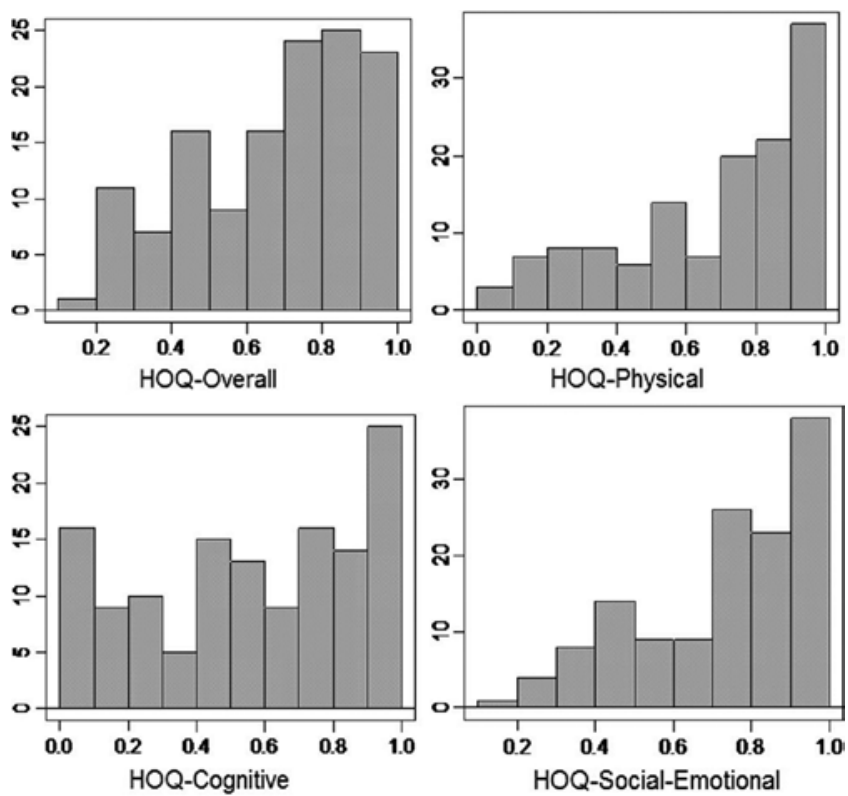

FIG. 1. Mean $\mathrm{HOQ}$ scores and their distribution (132 pediatric patients). 
TABLE 3. Characteristics of 132 pediatric patients with hydrocephalus

\begin{tabular}{|c|c|}
\hline Characteristic & $\%$ (no.) \\
\hline \multicolumn{2}{|l|}{ Hydrocephalus etiology } \\
\hline Posthemorrhage & $31.1(41)$ \\
\hline Primary & $18.2(24)$ \\
\hline Tumor associated & $16.7(22)$ \\
\hline Spinal dysraphism associated & $13.6(18)$ \\
\hline Postinfection & $10.6(14)$ \\
\hline Dysgenetic & $6.1(8)$ \\
\hline Other secondary cause & $3.8(5)$ \\
\hline \multicolumn{2}{|l|}{ Seizures } \\
\hline Yes & 34.8 \\
\hline No & 65.2 \\
\hline Intractable & 9.8 \\
\hline \multicolumn{2}{|l|}{ Visual impairment } \\
\hline Yes & 33.3 \\
\hline No & 66.7 \\
\hline \multicolumn{2}{|l|}{ Hearing impairment } \\
\hline Yes & 5.3 \\
\hline No & 94.7 \\
\hline \multicolumn{2}{|l|}{ Motor impairment } \\
\hline Yes & 26.5 \\
\hline No & 73.5 \\
\hline \multicolumn{2}{|l|}{ Shunt infection } \\
\hline Yes & 13.6 \\
\hline No & 86.4 \\
\hline \multicolumn{2}{|l|}{ Symptomatic overdrainage } \\
\hline Yes & 60.6 \\
\hline No & 39.4 \\
\hline \multicolumn{2}{|l|}{ Shunt revision } \\
\hline Yes & 69.7 \\
\hline No & 30.3 \\
\hline \multicolumn{2}{|c|}{ Parents' education level (higher of both) } \\
\hline Preprimary & 3.8 \\
\hline Primary & 24.4 \\
\hline Secondary & 38.9 \\
\hline Tertiary & 32.8 \\
\hline \multicolumn{2}{|l|}{ Adjuvant care } \\
\hline None & 22.7 \\
\hline Physical therapy & 13.6 \\
\hline Neuropsychological & 15.2 \\
\hline Both & 30.3 \\
\hline Not needed & 18.2 \\
\hline
\end{tabular}

nosis. All of the parents agreed that functional prognosis was a main concern after hearing their child's diagnosis. Given that Kulkarni et al. ${ }^{14}$ found that parents' and surgeons' global ratings of a child's health were correlated only moderately with the HOQ overall health scores, we were rigorous about not influencing the parents' answers. Thus, the HOQ can be considered a tool for the assess-
TABLE 4. Number of shunt revisions at the time of the study

\begin{tabular}{ccc}
\hline No. of Shunt Revisions & No. of Patients & $\%$ \\
\hline 0 & 34 & 25.8 \\
\hline 1 & 33 & 25.0 \\
\hline 2 & 26 & 19.7 \\
\hline 3 & 21 & 15.9 \\
\hline 4 & 7 & 5.3 \\
\hline 5 & 7 & 5.3 \\
\hline 6 & 2 & 1.5 \\
\hline 7 & 1 & 0.8 \\
\hline 8 & 1 & 0.8 \\
\hline Total & 132 & $100.1^{*}$ \\
\hline
\end{tabular}

* Value exceeds $100 \%$ because of rounding.

ment of quality of life in our patients in a relatively quick and easy fashion,,$^{14}$ which should prove valuable for our clinical practice.

The Spanish National Health System has had universal free coverage since 1989; responsibility has belonged to each autonomous community since 2002 (with the exception of Ceuta and Melilla, which are regulated by the central government, which also performs coordination tasks). The most important goals of our health care system are equity, quality, and accessibility. In Andalusia, every child younger than 6 years with or at risk for a developmental delay is referred by his or her pediatrician to attend (with the parents) multidisciplinary units coordinated by health, education, and social offices, created for the prevention, diagnosis, and treatment of functional disorders. From the ages of 6 to 16 years, most of these children can be educated in an ordinary school, sometimes with specialized support, or, in exceptional cases (e.g., severe developmental delay or cognitive impairment and multiple deficiency), in specific centers.

Comparison of our HOQ results with others reveals that the mean scores are quite similar despite the different environments (Table 9), and wide individual variability of the scores also was seen. Previous studies found that approximately $10 \%$ of the variance in HOQ scores is attributable to parental factors; pediatric factors were the main influence on HOQ scores. ${ }^{14}$ We believe that the wide individual variability in HOQ scores reflects the intrinsic heterogeneity of this group of patients diagnosed with hydrocephalus at different ages and with different etiologies, treatments, and complications. As in previous reports, HOQ cognitive

TABLE 5. Mean HOQ scores of 132 pediatric patients with hydrocephalus

\begin{tabular}{lccccc}
\hline \multicolumn{1}{c}{ HOQ Score } & No. of Patients & Min & Max & Mean & SD \\
\hline Physical & 132 & 0.00 & 1.00 & 0.6892 & 0.27478 \\
\hline Social-emotional & 132 & 0.18 & 1.00 & 0.7348 & 0.21529 \\
\hline Cognitive & 132 & 0.00 & 1.00 & 0.5618 & 0.32063 \\
\hline Overall & 132 & 0.16 & 1.00 & 0.6801 & 0.22554 \\
\hline
\end{tabular}


TABLE 6. Reliability estimates for the $\mathrm{HOQ}-$ Spanish version

\begin{tabular}{lc}
\hline \multicolumn{1}{c}{ HOQ Score } & Internal Consistency (Cronbach alpha) \\
\hline Physical health & 0.923 \\
\hline Social-emotional & 0.767 \\
\hline Cognitive & 0.909 \\
\hline Overall health & 0.929 \\
\hline
\end{tabular}

scores were lower than physical or social-emotional scores, which represent the main limitation in these children. ${ }^{10,12}$

\section{Association Between Independent Variables and HOQ Scores}

Variables related to the quality of life measured with the HOQ in our study were compared with previously reported variables ${ }^{12,14,16}$ and are summarized in Table 10. As previously reported by our group, ${ }^{6,7}$ an important explanation for our high frequency of symptomatic overdrainage is that our definition did not include only patients with episodic headaches, slow valve refilling, or radiological ventricular collapse; it was based on a very strict protocol of detection and active treatment of overdrainage, and we included any patient whose symptoms (whatever they were) improved
TABLE 7. Association between dichotomous independent variables and $H O Q$ scores

\begin{tabular}{lcccc}
\hline \multirow{2}{*}{\multicolumn{1}{c}{ Variable }} & \multicolumn{5}{c}{$p$ Values According to } \\
& HOQ Health Aspect \\
\cline { 2 - 5 } & Physical & Social & Cognitive & Overall \\
\hline Seizures & $<0.001^{*}$ & $0.004^{*}$ & $<0.001^{*}$ & $<0.001^{*}$ \\
\hline Intractable seizures & $<0.001^{*}$ & $<0.001^{*}$ & $<0.001^{*}$ & $<0.001^{*}$ \\
\hline Visual impairment & $<0.001^{*}$ & $<0.001^{*}$ & $<0.001^{*}$ & $<0.001^{*}$ \\
\hline Hearing impairment & 0.840 & 0.283 & 0.99 & 0.794 \\
\hline Motor impairment & $<0.001^{*}$ & $0.002^{*}$ & $<0.001^{*}$ & $<0.001^{*}$ \\
\hline Shunt infection & $0.013^{*}$ & 0.142 & $0.002^{*}$ & $0.010^{*}$ \\
\hline Symptomatic overdrainage & 0.166 & 0.357 & $0.037^{*}$ & 0.073 \\
\hline Shunt-revision surgery & $0.013^{*}$ & 0.492 & 0.089 & 0.077 \\
\hline Parents' academic level† & 0.485 & 0.269 & 0.446 & 0.306 \\
\hline
\end{tabular}

* Significant result.

$\dagger$ The parents' academic level was stratified according to undergraduate versus graduate/professional degree.

after increasing shunt flow resistance (sometimes upgrading the system in place and other times changing the valve to add more resistance to the system in a revision surgery).

To improve quality of life in pediatric patients with hy-
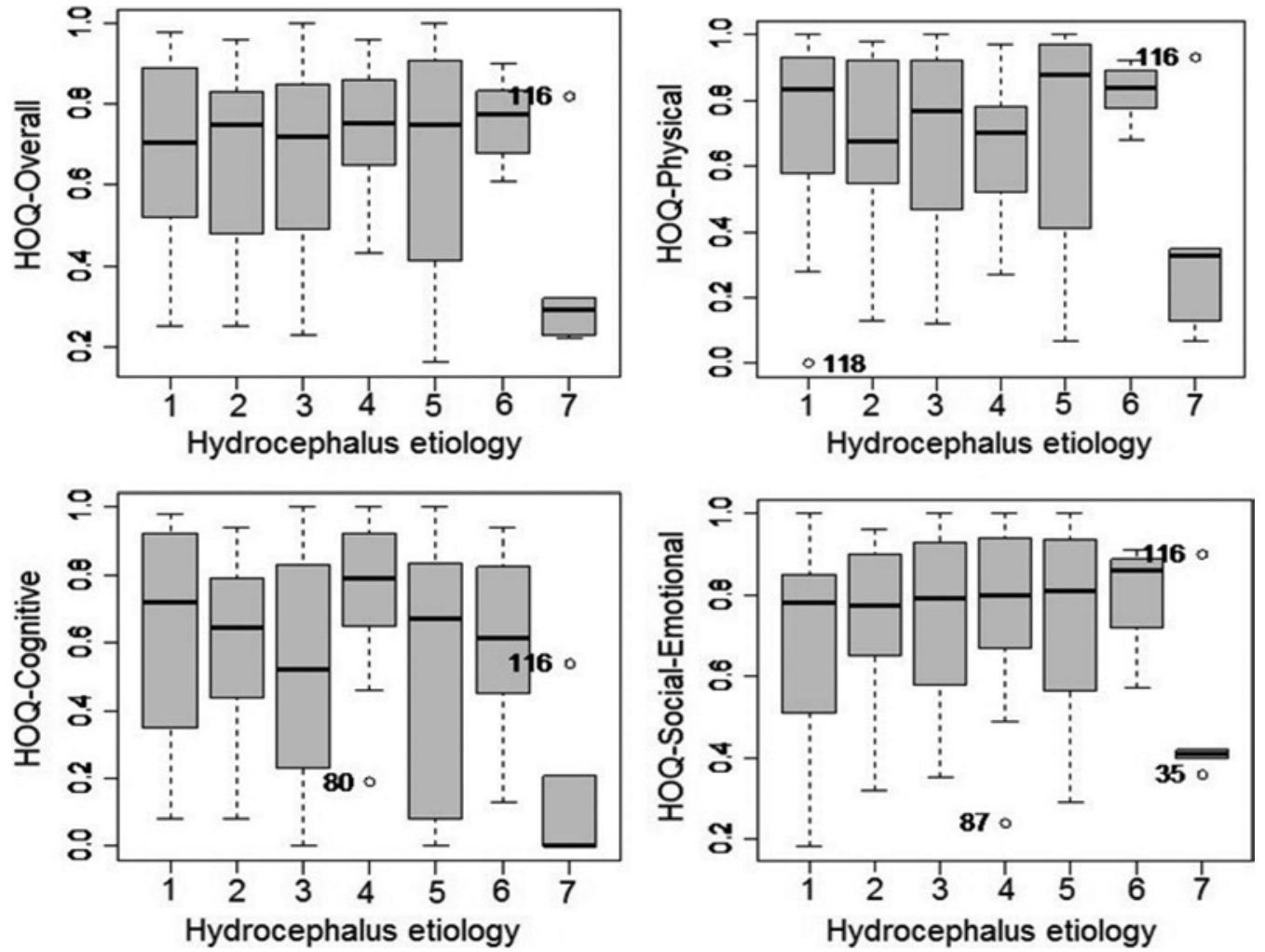

FIG. 2. Box plots showing the relationships between health scores and the etiology of hydrocephalus. Each box indicates the median, quartiles, and highest and lowest values within each category. $1=$ tumor-associated hydrocephalus; 2 = postinfection hydrocephalus; 3 = posthemorrhage hydrocephalus; 4 = spinal dysraphism-associated hydrocephalus; 5 = primary hydrocephalus; 6 $=$ dysgenetic hydrocephalus; 7 = other secondary hydrocephalus. 

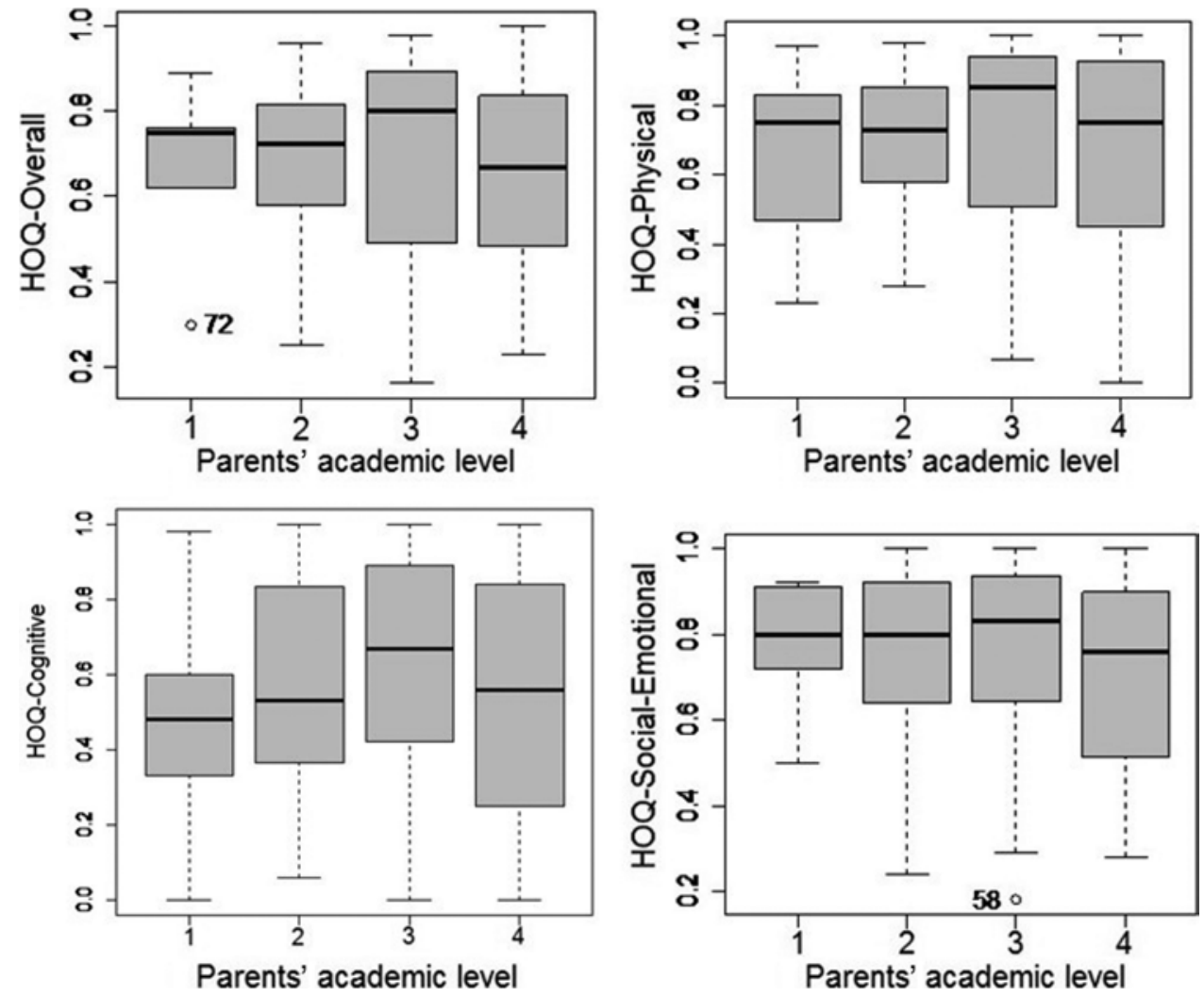

FIG. 3. Box plots showing the relationships between health scores and the degree of parental education. $1=$ preprimary education; 2 = primary education; 3 = secondary education; 4 = tertiary education.

drocephalus, our efforts and interventions should be directed at decreasing the shunt-infection rate, the number of shunt revisions, and overdrainage, because these factors were associated with a worse functional prognosis in our population, as in other centers. ${ }^{16,22}$ Such improvement will be the focus of our future research.

Regular control of quality of life during the follow-up period could inform physicians, parents, and educators about the child's health status, thus aiding cooperation and making available to the children all adjuvant therapies that could be beneficial to them.

We were unable to demonstrate a significantly worse outcome associated with any of the hydrocephalus etiologies, probably because of our small sample size. We also did not find any difference in outcomes depending on distance from the patient's house to our hospital, although the distances could have been underestimated. Some of our patients come from Melilla (a Spanish enclave in North Africa), and a few live in northern Morocco. Although these distances are not great in terms of kilometers, it nevertheless takes patients longer to arrive at the hospital because the families need to plan a ferry journey across the Mediterranean, and Moroccan patients require a visa. In fact, patients are lost to follow-up more frequently because of this situation than for any other reason.

The level of parental education (divided into 2 and 4 categories) and adjuvant therapy given to the patients were not significantly related to the children's quality of life, although this result might be related to the sample size and the multiple comparisons, both of which are parameters that could be affected by the wide coverage of our health care system that could decrease the impact of socioeconomic factors on quality of life. This result should be confirmed in future Spanish multicenter studies. Also true is

TABLE 8. Association between quantitative independent variables and HOQ scores

\begin{tabular}{|c|c|c|c|c|c|c|c|c|}
\hline \multirow[b]{2}{*}{ Variable } & \multicolumn{2}{|c|}{ HOQ Physical } & \multicolumn{2}{|c|}{ HOQ Social } & \multicolumn{2}{|c|}{ HOQ Cognitive } & \multicolumn{2}{|c|}{ HOQ Overall } \\
\hline & rValue & p Value & r Value & p Value & rValue & p Value & r Value & $\mathrm{p}$ Value \\
\hline Age at diagnosis & 0.083 & 0.348 & 0.151 & 0.085 & 0.16 & 0.858 & -0.034 & 0.698 \\
\hline Age at $\mathrm{HOQ}$ & -0.136 & 0.122 & $-0.235^{\star}$ & $0.007^{*}$ & -0.101 & 0.248 & $-0.190^{*}$ & $0.029^{*}$ \\
\hline No. of shunt-revision surgeries & $-0.204^{*}$ & $0.019^{*}$ & -0.086 & 0.328 & -0.161 & 0.065 & -0.170 & 0.051 \\
\hline Distance to hospital & -0.055 & 0.530 & 0.072 & 0.411 & -0.156 & 0.075 & -0.035 & 0.687 \\
\hline
\end{tabular}

The $\mathrm{r}$ values represent Pearson correlation coefficients.

* Significant result. 

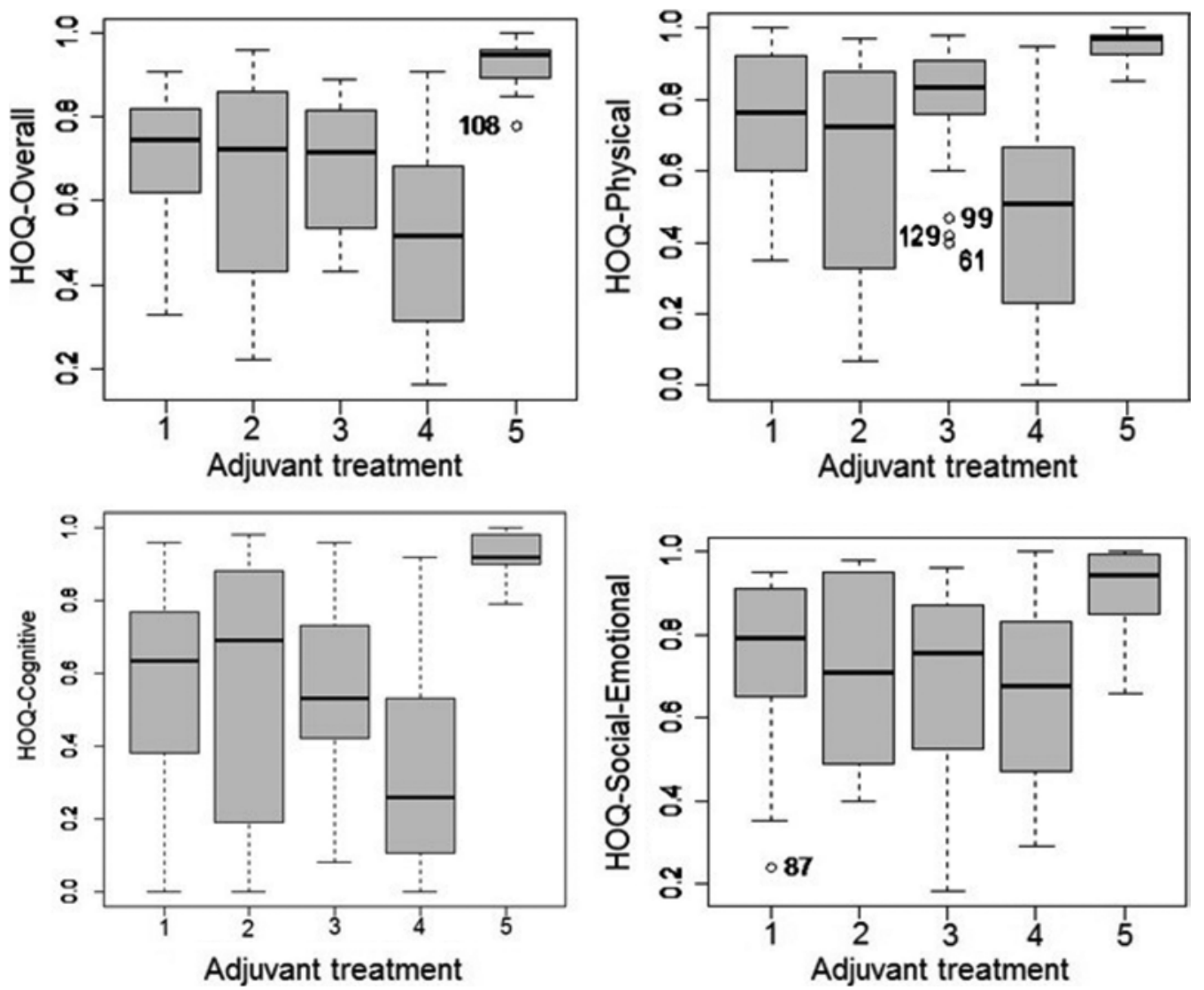

FIG. 4. Box plots showing the relationships between health scores and adjuvant treatment received by the patient. $1=$ none; $2=$ physical therapy; $3=$ neuropsychological therapy; $4=$ both types of therapy; $5=$ therapy not needed.

that many of these families give additional treatment to their children to improve or at least maintain their health status. Nevertheless, a matter of concern is those children outside the special education system who do not undergo any kind of treatment and have a low score. In these cases, the parents knew their children's limitations, but they rejected the recommended school for other reasons (distance to the school, other school preferences, maintain all their children at the same place, etc.). These results, though, are not generalizable to other countries, because they would differ depending on the health system model. ${ }^{12}$

The HOQ is not an age-normed scale, but it was designed with several sets of parents representing children of various ages with various hydrocephalus causes. ${ }^{15}$ As in previous reports,,$^{11,12,14-16,24}$ only children 5 years of age or older were included in our study, because health status issues for younger children and infants would likely differ greatly from those of school-aged children. The mean, median, standard deviation, and range of ages in our study were similar to those in previous studies, ${ }^{12,14,16}$ with the exception of the Platenkamp et al. study, which included a sample that was more homogeneous than ours. ${ }^{24}$ In fact, other than ours, only 1 report documented a significant association between HOQ scores and patient age, ${ }^{12}$ and that result was attributed to a spurious finding. Our analysis revealed a significant association between patient age at the time of the study and HOQ social-emotional and overall scores. For the social-emotional score, personality and social development is a process during childhood that is related also to mental development. Problems derived from poor emotional control and low self-esteem or social ability are more patent in adolescence and adulthood than they

TABLE 9. Mean HOQ score comparison

\begin{tabular}{|c|c|c|c|c|c|c|}
\hline \multirow[b]{2}{*}{ Authors \& Year } & \multicolumn{4}{|c|}{$\mathrm{HOQ}$} & \multirow{2}{*}{$\begin{array}{l}\text { Utility } \\
\text { Score }\end{array}$} & \multirow{2}{*}{$\begin{array}{c}\text { Sample } \\
\text { Size }\end{array}$} \\
\hline & Physical Score & Social-Emotional Score & Cognitive Score & Overall Score & & \\
\hline Kulkarni et al., $2004^{14}$ & 0.71 & 0.72 & 0.57 & 0.68 & 0.77 & 80 \\
\hline Kulkarni et al., 2007 & 0.71 & 0.72 & 0.57 & 0.68 & 0.77 & 346 \\
\hline Platenkamp et al., 2007 & 0.66 & 0.78 & 0.54 & 0.69 & 0.77 & 107 \\
\hline Current study & 0.69 & 0.73 & 0.56 & 0.68 & 0.77 & 132 \\
\hline
\end{tabular}


TABLE 10. Predictors of worse outcomes related to HOQ scores

\begin{tabular}{|c|c|c|c|c|}
\hline \multirow[b]{2}{*}{$\begin{array}{l}\text { HOQ Health } \\
\text { Aspect }\end{array}$} & \multicolumn{4}{|c|}{ Factors According to Study } \\
\hline & $\begin{array}{l}\text { Kulkarni et al., } \\
2004^{14}\end{array}$ & Kulkarni et al., 2007 & Kulkarni et al., 2008 ${ }^{12}$ & Current Study \\
\hline \multirow[t]{8}{*}{ Physical } & Seizures & Seizures & Household income $>\$ 100,000 / y r$ & Seizures \\
\hline & & Catheters & Family functioning & Visual impairment \\
\hline & & Time until shunt & Seizures & Motor impairment \\
\hline & & Distance to hospital & Myelomeningocele & Shunt infection \\
\hline & & Premature birth & Age at assessment & Shunt revision \\
\hline & & Length of admission (shunt infection) & Average annual length of hospital stay & No. of shunt-revision surgeries \\
\hline & & $\begin{array}{l}\text { Diagnosis other than IVHP or aqueductal } \\
\text { stenosis }\end{array}$ & & \\
\hline & & Increased current ventricular size & & \\
\hline \multirow[t]{4}{*}{ Social-emotional } & Seizures & Seizures & Household income $>\$ 100,000 / y r$ & Seizures \\
\hline & & Catheters & Family functioning & Visual impairment \\
\hline & & Duration of admission (overdrainage) & Seizures & Motor impairment \\
\hline & & Increased initial ventricular size & & Age at HOQ completion \\
\hline \multirow[t]{5}{*}{ Cognitive } & Seizures & Seizures & Household income $>\$ 100,000 / y r$ & Seizures \\
\hline & Shunt revisions & $\begin{array}{l}\text { Duration of admission (shunt infection \& } \\
\text { first treatment) }\end{array}$ & Parent university degree & Visual impairment \\
\hline & & Younger age at first surgery & Family functioning & Motor impairment \\
\hline & & & Seizures & Shunt infection \\
\hline & & & & Overdrainage \\
\hline \multirow[t]{5}{*}{ Overall } & Seizures & Seizures & Household income $>\$ 100,000 / y r$ & Seizures \\
\hline & & Catheters & Parent university degree & Visual impairment \\
\hline & & $\begin{array}{l}\text { Duration of admission (shunt infection, } \\
\text { overdrainage, \& first treatment) }\end{array}$ & Family functioning & Motor impairment \\
\hline & & Distance to hospital & Seizures & Shunt infection \\
\hline & & & Myelomeningocele & Age at HOQ completion \\
\hline
\end{tabular}

IVHP = intraventricular hemorrhage of prematurity.

are earlier in childhood. It also is possible that the parents' perception of the social-emotional status of their children can become more pessimistic with the passing of time. We should remember also that social-emotional scores were in greater disagreement when the scales between the parents' and the children's perspectives were compared, ${ }^{11}$ and it is the dimension with the lowest reliability coefficient.

Only a few studies have documented the long-term effects of childhood hydrocephalus on quality of life., ${ }^{2,18,23,25}$ Most of them found different degrees of impact on mental and physical health, social integration, employment achievement, and independent life in adulthood.

Just as the 20th century involved shunt-surgery development and a reduction in the mortality rate related to pediatric hydrocephalus, the 21 st century should be the time to achieve consensus, to look for new pathophysiological theories and etiology-based treatments, and to measure and compare our results not only according to technical aspects but also in terms of quality of life. For this last goal, the HOQ is a valuable and easy tool that can be used.

Future efforts should be aimed at further understanding the multidimensional health of pediatric patients with hydrocephalus to decrease factors related to worse outcome and to improve access to adjuvant therapies.

\section{Limitations}

The major limitations of this study concern its singlecenter nature, the retrospective assessment of some independent variables, and the low total number of patients in the sample.

We also performed a large amount of statistical analysis on our 132 patients, which inflated the alpha error and can lead to false-positive findings. Nevertheless, the results obtained were similar to those of the largest studies reported from referral centers. ${ }^{12,16}$ This limitation should be considered in future Spanish multicenter studies.

Our patient selection also could have missed those who did not attend the clinics because they were doing very well or very poorly. Nonetheless, losses to follow-up at our institution are infrequent given the accessibility of the hospital and close follow-up that we provide (frequently more than twice per year). Last, we also note that health outcomes were measured using answers from the parents, which could differ from those of the children.

\section{Conclusions}

Ours is only the second study outside Canada to use the HOQ to assess the quality of life of pediatric patients 
who have undergone shunt placement to treat hydrocephalus. The HOQ-Spanish version is useful for evaluating the patients in our region, and the reported measures of quality of life are comparable to those previously reported by referral centers. A history of seizures and motor or visual impairment were related to a worse score in all HOQ dimensions. Shunt infection was related to worse physical, cognitive, and overall scores. A history of shunt revision and more than 2 shunt-revision surgeries (range $0-8$ revisions) were predictors of a worse physical HOQ score, and symptomatic overdrainage was associated with a worse cognitive outcome. Older age at the time of the study was related to worse social-emotional and overall outcomes. Future goals should be preventing factors related to worse outcomes and improving access to adjuvant therapy.

\section{Acknowledgments}

We are grateful to Dr. Abhaya Kulkarni for providing us with the HOQ data collection and score calculation software.

\section{References}

1. Bui CJ, Tubbs RS, Shannon CN, Acakpo-Satchivi L, Wellons JC III, Blount JP, et al: Institutional experience with cranial vault encephaloceles. J Neurosurg 107 (1 Suppl):22-25, 2007

2. Gupta N, Park J, Solomon C, Kranz DA, Wrensch M, Wu YW: Long-term outcomes in patients with treated childhood hydrocephalus. J Neurosurg 106 (5 Suppl):334-339, 2007

3. Heinsbergen I, Rotteveel J, Roeleveld N, Grotenhuis A: Outcome in shunted hydrocephalic children. Eur J Paediatr Neurol 6:99-107, 2002

4. Hirsch JF: Consensus: long-term outcome in hydrocephalus. Childs Nerv Syst 10:64-69, 1994

5. Hoppe-Hirsch E, Laroussinie F, Brunet L, Sainte-Rose C, Renier D, Cinalli G, et al: Late outcome of the surgical treatment of hydrocephalus. Childs Nerv Syst 14:97-99, 1998

6. Iglesias S, Ros B, Martín Á, Carrasco A, Segura M, Delgado A, et al: Surgical outcome of the shunt: 15-year experience in a single institution. Childs Nerv Syst 32:2377-2385, 2016

7. Iglesias S, Ros B, Martín Á, Carrasco A, Segura M, Ros A, et al: Factors related to shunt survival in paediatric hydrocephalus. Could failure be avoided? Neurocirugia (Astur) 28:159-166, 2017

8. Kestle JR, Holubkov R, Douglas Cochrane D, Kulkarni AV, Limbrick DD Jr, Luerssen TG, et al: A new Hydrocephalus Clinical Research Network protocol to reduce cerebrospinal fluid shunt infection. J Neurosurg Pediatr 17:391-396, 2016

9. Klimo P Jr, Kestle JR: Potentially useful outcome measures for clinical research in pediatric neurosurgery. $\mathbf{J}$ Neurosurg 103 (3 Suppl):207-212, 2005

10. Kulkarni AV: Quality of life in childhood hydrocephalus: a review. Childs Nerv Syst 26:737-743, 2010

11. Kulkarni AV, Cochrane DD, McNeely PD, Shams I: Comparing children's and parents' perspectives of health outcome in paediatric hydrocephalus. Dev Med Child Neurol 50:587592, 2008

12. Kulkarni AV, Cochrane DD, McNeely PD, Shams I: Medical, social, and economic factors associated with health-related quality of life in Canadian children with hydrocephalus. $\mathbf{J}$ Pediatr 153:689-695, 2008

13. Kulkarni AV, Donnelly R, Shams I: Comparison of Hydrocephalus Outcome Questionnaire scores to neuropsychological test performance in school-aged children. J Neurosurg Pediatr 8:396-401, 2011

14. Kulkarni AV, Drake JM, Rabin D, Dirks PB, Humphreys RP, Rutka JT: Measuring the health status of children with hydro- cephalus by using a new outcome measure. J Neurosurg 101 (2 Suppl):141-146, 2004

15. Kulkarni AV, Rabin D, Drake JM: An instrument to measure the health status in children with hydrocephalus: the Hydrocephalus Outcome Questionnaire. J Neurosurg 101 (2 Suppl):134-140, 2004

16. Kulkarni AV, Shams I: Quality of life in children with hydrocephalus: results from the Hospital for Sick Children, Toronto. J Neurosurg 107 (5 Suppl):358-364, 2007

17. Kulkarni AV, Shams I, Cochrane DD, McNeely PD: Quality of life after endoscopic third ventriculostomy and cerebrospinal fluid shunting: an adjusted multivariable analysis in a large cohort. J Neurosurg Pediatr 6:11-16, 2010

18. Kutscher A, Nestler U, Bernhard MK, Merkenschlager A, Thome U, Kiess W, et al: Adult long-term health-related quality of life of congenital hydrocephalus patients. J Neurosurg Pediatr 16:621-625, 2015

19. Lumenta CB, Skotarczak U: Long-term follow-up in 233 patients with congenital hydrocephalus. Childs Nerv Syst 11:173-175, 1995

20. Mataró M, Junqué C, Poca MA, Sahuquillo J: Neuropsychological findings in congenital and acquired childhood hydrocephalus. Neuropsychol Rev 11:169-178, 2001

21. Mori K, Shimada J, Kurisaka M, Sato K, Watanabe K: Classification of hydrocephalus and outcome of treatment. Brain Dev 17:338-348, 1995

22. Oakes WJ: Long-term outcomes of hydrocephalus. J Neurosurg 106 (5 Suppl):333, 2007

23. Paulsen AH, Lundar T, Lindegaard KF: Pediatric hydrocephalus: 40 -year outcomes in 128 hydrocephalic patients treated with shunts during childhood. Assessment of surgical outcome, work participation, and health-related quality of life. J Neurosurg Pediatr 16:633-641, 2015

24. Platenkamp M, Hanlo PW, Fischer K, Gooskens RH: Outcome in pediatric hydrocephalus: a comparison between previously used outcome measures and the Hydrocephalus Outcome Questionnaire. J Neurosurg 107 (1 Suppl):26-31, 2007

25. Preuss M, Kutscher A, Wachowiak R, Merkenschlager A, Bernhard MK, Reiss-Zimmermann M, et al: Adult long-term outcome of patients after congenital hydrocephalus shunt therapy. Childs Nerv Syst 31:49-56, 2015

26. Scott MA, Fletcher JM, Brookshire BL, Davidson KC, Landry $\mathrm{SH}$, Bohan TC, et al: Memory functions in children with early hydrocephalus. Neuropsychology 12:578-589, 1998

27. Topczewska-Lach E, Lenkiewicz T, Olański W, Zaborska A: Quality of life and psychomotor development after surgical treatment of hydrocephalus. Eur J Pediatr Surg 15:2-5, 2005

28. Vinchon M, Rekate H, Kulkarni AV: Pediatric hydrocephalus outcomes: a review. Fluids Barriers CNS 9:18, 2012

\section{Disclosures}

The authors report no conflict of interest concerning the materials or methods used in this study or the findings specified in this paper.

\section{Author Contributions}

Conception and design: Iglesias, Ros. Acquisition of data: Iglesias, Ros, Martín, Carrasco. Analysis and interpretation of data: Iglesias. Drafting the article: Iglesias, Ros, Martín, Carrasco. Critically revising the article: all authors. Reviewed submitted version of manuscript: all authors. Approved the final version of the manuscript on behalf of all authors: Iglesias. Statistical analysis: Rius.

\section{Correspondence}

Sara Iglesias: Hospital Regional Universitario de Málaga, Spain. siglesias95@yahoo.es. 